\title{
Formation of the Institution of Environmental Responsibility of Coal Industry Enterprises
}

\author{
Nikolay Bondarev ${ }^{1}$, Galina Bondareva $^{1}$, Nikita Ravochkin ${ }^{1, *}$, and Valentina Windemut $^{2}$ \\ ${ }^{1}$ Kemerovo State Agricultural Institute, 6500565 Markovtseva str., Kemerovo, Russia \\ ${ }^{2}$ Charité - Universitätsmedizin Berlin, 101171 Charitéplatz, Berlin, Germany
}

\begin{abstract}
In this article the authors analyze the formation of an institution of environmental responsibility developing a modern view on the practice of corporate social responsibility, taking into account the specifics of Russian enterprises in the coal industry. The study emphasizes the importance of considering the ecological aspect and environmental protection, which is becoming relevant in the context of the implementation of anthropogenic and man-made impacts on the nature caused by industry. A comparison is made in terms of time awareness by foreign and domestic enterprises of the coal industry of a responsible attitude to the biosphere and ecosystems. The environmental aspect is marked as integral to the coal industry. It is substantiated that the formation of the institution of environmental responsibility of coal industry enterprises reflects the impossibility of taking into account all the needs of target audiences with corporate social responsibility events. It is clarified that the need for the formation of this institution is given by megatrends of civilizational development. In conclusion, the study provides the starting points for the implementation of the processes of the formation of the institution of environmental responsibility.
\end{abstract}

\section{Introduction}

The relevance of the study is defined by the intransient essence of institutions, their importance in the life of society and the state, by the need to master the global experience to the governments. The consumption in its various aspects is presented as the most acute problem of mankind. The problem of the environment saving development of the planetary civilization in the XXI century looks especially relevant and obvious today. Additional threats create opportunities for the loss of the whole natural resistance of the relevant ecosystems as the ability of the biosphere to assimilate the effects of anthropogenic impacts [1]. Any human activity to a certain extent affects nature, having a difference only in the scale of the impact. Of course, most often this influence is marked as negative, which also does not contribute to the improvement of living standards and the preservation of living conditions in general. Today, there is a multiplication of the number of such influencing factors, as well as their interrelation, which is significantly complicated [2].

\footnotetext{
* Corresponding author: nickravochkin@mail.ru
} 
Taking into account the issues and problems of the social and environmental responsibility of Russian coal enterprises in recent years has been closely associated with the growing influence of these companies on the environment conditions. Coal mining is a source of various emissions that suppress ecology of the region. If we consider in more detail, the coal industry enterprises change the landscape, relief, pollute the biosphere with various types of emissions and other compounds [3].

In addition, more than the half of Russian citizens living in adjacent areas to coal mining enterprises are agitated by the state of the environment in their places of residence. Thus, if at the end of the twentieth century the minor of people paid attention to the state of ecology in coal-mining regions, living according to the principle "earn here and now", then today the greening trends were pronounced as the main imperative [4]. This is due to the technogenic type of development of the modern economy, which leads to the degradation of natural resources, covering a rather long, sometimes for the lifetime of several generations, period for their recovery. In turn, in the context of globalization the entire public draws attention and positively estimates a business that cares about the future state of environment. Ecologically-responsible entrepreneurship reduces the amount of negative external effects, cuts the negative anthropogenic impact on the ecological system, coordinating and satisfying individual, group and public environmental concerns and needs [3].

Summarizing the statement of the problem of this study, the authors believe that it is necessary to move away from non-systemic manifestations of environmentally responsible behavior of coal industry enterprises to the formation of a comprehensive institution of environmental responsibility in the context of a common corporate social policy of enterprises.

\section{Materials and Methods}

The realities of globalization and international competition set a multiple complex of interrelated tasks for modern coal enterprises. The successful solution of most of them is due to competent management activities and implies considering modern managerial paradigms. Environmental responsibility is a new phenomenon, which, moreover, has a plural meaning. If until the 1990s, in Russian business realities, it was translated in legal and economic terms, but today it also acquires an environmental comprehension $[5,6]$.

For comparison, in the states of Europe and the USA nature conservation has been a priority for the development of the coal mining business since the middle of the last century. This is evidenced by at least the presence of environmental programs, developed and updated environmental legislation. In this context, we also note the present activities of political parties of the "green" and relevant public organizations that have an increasingly significant impact on the business practices of coal-mining enterprises [7].

A clear formulation and implementation of the environmental objectives of coal enterprises is becoming an integral part of modern quality management in subsoil extraction. An important element of an effective enterprise system is a high level of corporate responsibility and the subsequent identity of external and internal target groups. Western business has already come to the need to identify its own functions and roles in environment development and interaction in the realities of the conflicting interests of various social and ecological actors [8].

According to the author's opinion, environmental responsibility in the context of corporate social responsibility is a voluntary investment of enterprises in solving problems of injustice in the distribution of natural resources and reducing tensions in society in order to avoid global economic losses and to strengthen rivalry. It should be noted that the environmental component of any coal production due to the practically maximum load on 
the environment is an integral assessment indicator of the industry. Taking into account the environmental factors of coal production at the initial stage pf industrial strategic planning is not only the initiative of the enterprise itself, but also the state, in tandem with which the business should participate in the process of caring for the nature preservation [9].

The solution of issues of anthropogenic pressure on the nature often faces different directions of actions. According to the economic tendencies of the profit aspirations in business structures, they are interested in minimizing their expenses, including environmental and economic ones. Therefore, the state is limiting their actions through, for example, the initiation and adoption of relevant norms of environmental laws. Without government regulation of environmental actions or inactions that are not interested in environmentally responsible behavior, much more money will be required to cover the damage to the nature. In turn, the state is interested in business, because it provides jobs, and also guarantees revenues to the budget. As practice shows, coal enterprises play the role of city-forming ones. Nevertheless, some cases indicate the occurrence of back pressure - forcing coal mining companies to environmental cleanliness can lead to closure. Moreover, such situations are even more aggravated in the industrialized coal mining regions [5].

Nevertheless, the consideration of positive and negative examples reveals the need to form an institution for the environmental responsibility of coal enterprises. In our opinion, this institution is invariably linked not only with the economy and society, but also with the system of political power, culturally and legally defined relations between members of the community.

\section{Results and Discussion}

We emphasize that the institution of responsibility already exists in the field of coal industry companies. However, in its present form, it already appears to be ineffective due to competitive pressure, and, therefore, can be considered only as an example of socioeconomic memory. The nature of competition between coal-mining enterprises and their ambitious aspirations objectively necessitates their advantageous positioning, and the "win to win" gain, which implies a subsequent increase in the popularity of the brand they create. The experience of some coal mining enterprises shows that the best practices of responsible behavior were the creation of their own medical centers and corporate universities, the payment for the vacations of employees and their families, the attendance of labor veterans and much more. However, today mankind is aware that the greatest effect will be achieved when the principles of social responsibility will be in syncretism with environmentally responsible behavior.

Therefore, there is the need to analyze existing institutions in comparison with the alternatives presenting in reality, and not with simulated systems, which theoretically should act more efficiently. Rational choice theory directs institutional analysis towards studying the strategic actions of individuals (actors), determining that rational actors perform most rationally for themselves, scaling rationality at the macro level, and using institutions as means of solving the problem of individual rationality.

The Institution for Environmental Responsibility appears in the approach presented by D. North as new "rules of conduct" [10] for domestic coal mining enterprises, allowing them to integrate into the international institutional environment. Indeed, the goal of domestic coal industry enterprises as players is winning in the rivalry. However, overcoming egoistic sentiments should also mean a public scoring. Today, the inconstancy of many social phenomena is particularly noticeable. An increasing number of norms and rules of behavior is being replaced or transformed in the segment of one generation life. In cases when the representatives of the new generation are born in the time interval, the 
corresponding configuration of the selection of the characteristics of socialization of the representatives of this generation is carried out.

Therefore, the formation of an institution of environmental responsibility in the context of the social responsibility indicates the effectiveness of actions to change the norms and introduce such rules of the game, which are largely predetermined by megatrends. This is where the basis of socially responsible practices is seen, to which the attention should be paid by the management of coal enterprises. Mainly, the need for corporate environment responsibility by enterprises' management is determined by the need for understanding the essence of economic reality and the trends that accompany the development of the coal industry. Understanding and subsequent awareness become possible through the knowledge of the patterns of their functioning and behavioral reactions that create not only waiting models of agents, but a model of advancing actions and further assessments. The formation of this institution will "force" coal enterprises to concur with their activities with a certain uniformity and create repeated cycles of behavior in similar situations, applying punishment for deviant actions.

With all this, it is worth paying attention to some areas of the environmental responsibility of coal enterprises. So, given their close relationship with agricultural areas, the ongoing development of the agro-industrial complex looks like one of the promising areas of environmentally responsible behavior. Also, the initiative for the restoration of disturbed land and the re-use of coal waste is a positive marker. It should be noted that the proposed institutional arrangement will allow to solve the following number of issues:

- consolidation and harmonious coexistence of different social groups;

- smoothing and regulation of social contradictions;

- equitable distribution of resources;

- regulation of labor and production relations;

- openness and creation of the least conflicting conditions for the further development of relations between enterprises of the coal industry, the state and target groups.

\section{Conclusions}

Current trends of environmental development of the country require an instant adaptation to permanently changing and complicating conditions from the coal companies' management. Therefore, the high standards of environmental activities require coal mining business to make serious investments in this area. However, for the time being, a responsible approach to nature preserving investments and environmental initiatives are carried out by the business considering profits calculations. "What will we do in the future and how will the public evaluate us?" - this is the first question that should be asked by the management of coal enterprises. Thus, the starting point for the creation and development of the institution of environmental responsibility of coal enterprises is their awareness of the environmental damage inflicted over the years and the voluntary desire to minimize its consequences with a strong positive positioning effect. Therefore, transitions from the principle of "Paying for the right to pollute" to the sustainable development of territories are already noticeable today.

Aspirations for the creation of an institution of environmental responsibility of coal enterprises will be realized if the vectors of development of the economy, society and nature coincide, but in no way will they move to antagonistic relations. Today, the practice of Russian coal enterprises has accumulated sufficient experience that does not require blind copying of Western approaches to environmental protection, but which takes into account the domestic context of doing business in this industry. Indeed, today it no longer looks utopian, since a large part of coal enterprises consists of large companies that have the resources to implement projects in the field of environmental responsibility and the 
construction of environmental communication systems, through which the formation of an institution will have a positive effect for many stakeholders.

\section{References}

1. A. Marques, J. Rodrigues, M. Lenzen, T. Domingos, Ecological Economics, 84, 57-65 (2012) DOI: doi.org/10.1016/j.ecolecon.2012.09.010

2. S. Kovalevsky, N. Ravochkin, V. Shchennikov, E3S Web Conf., 41, 04035 (2018)

3. P. Heindl, P. Kanschik, Ecological Economics, 126, 42-50 (2016) DOI: doi.org/10.1016/j.ecolecon.2016.03.019

4. I. Dzeraviaha, Ecological Economics, 148, 15-21 (2018) DOI: doi.org/10.1016/j.ecolecon.2017.10.024

5. T. Frederiksen, The Extractive Industries and Society, 6:1, 162-170 (2019) DOI: doi.org/10.1016/j.exis.2018.07.007

6. S.O. Idowu, M. Aluchna, The Dynamics of Corporate Social Responsibility: A Critical Approach to Theory and Practice (Springer, New York, 2016)

7. S. Guifeng, S. Jianfei, Z. Li, J. Yufang, Journal of Accounting and Public Policy, 36:6, 417-428 (2017) DOI: doi.org/10.1016/j.jaccpubpol.2017.09.001

8. V.I. Panov, Procedia - Social and Behavioral Sciences, 86, 379-383 (2013) DOI: doi.org/10.1016/j.sbspro.2013.08.583

9. D.O. Smolennikov, Problems and Prospects of the Economy and Management, 1:5, 158167 (2016)

10. D. C. North, Institutions, Institutional Change and Economic Performance (Cambridge University Press, Cambridge, 1990) 